\title{
Industrialized building system - an innovative construction method
}

\author{
Anis Saggaff ${ }^{1^{*}}$ \\ ${ }^{1}$ Civil Engineering Department, Faculty of Engineering, Universitas Sriwijaya, 30662 Indralaya, Sumatera Selatan, Indonesia
}

\begin{abstract}
Industrialized building system (IBS) has been introduced in construction industry as early as 1960's. The challenges facing our construction industry are due to shortage of skill labour and high cost of construction. Therefore, the concept of construction using IBS is proposed to reduce our dependency on intensive labor works and to reduce the cost of construction. However, the process of changing the traditional construction method to IBS has been delayed due to the reluctant to accept the changes and even resistant to changes. Therefore this paper presents the concept of Industrialized Building System, the scope of IBS, challenges and way forward to inculcate the use of IBS construction in Indonesia.
\end{abstract}

\section{Introduction}

Housing needs continue to rise very rapidly in Indonesia, particularly in urban areas. Back log on housing needs up to 2016 has reached up to 7.6 million units, while demand for new homes every year has reached up to 800,000 units [1]. There are about $1,350,000$ units gap that must be resolved in order to fulfill the housing need in Indonesia [1]. One of the ways to speed up the construction of these affordable housing is to use Industrialized Building System (IBS) in construction. Industrialized Building System is usually associated with sustainable construction which is described as the ability of the construction system to consider the environmental impact of a building over its entire lifetime, while optimizing its economic viability and the comfort and safety of its occupants [2]. Typical standard building practices are guided by short term economic considerations; while IBS construction is based on best practices which emphasize on long term affordability, quality and efficiency. At each stage of life cycle of the building, it increases comfort and quality of life, while decreasing negative environmental impacts and increasing the economic sustainability of the project [3]. The concept of IBS usually associates with the preservation of the environment which also concern on related issues such as the efficient use of resource, continual social progress, promising economic growth, and improve standard of living. The main goals of IBS construction are to meet present day needs for housing, working environments and infrastructure without compromising the ability of future generations to meet their own needs in times to come. In Indonesia, typical building construction is usually associates with construction system based on typical reinforced concrete design where formwork is formed using timber and plywood while the concrete is cast in-situ. As IBS system is quite new in Indonesia, a way forward to motivate and promote the system is a big challenge to the Indonesia construction industry.

This paper generally discussed on issues facing our construction industry and current researches related to the use of Industrialized Building System (IBS). One of the main problems facing our construction industry is a serious shortage of skill construction workers. Therefore, the introduction of Industrialized Building System (IBS) by Indonesia Government is a good alternative to reduce the dependency on skill workers. However, the use of IBS as an alternative to conventional system (reinforced concrete) has not widely accepted by construction industry players. Some of negative perceptions given by construction industry players on the use of IBS are listed as not ready towards new concept, insufficient information and lack of knowledge to understand changes in IBS. Hervas revealed that construction sector is known as traditional sector that can be identified as not willing to accept changes or even resist changing [4]. This paper also discusses the current implementation of IBS, its shortcomings and the way to enhance the system forward. It also elaborates the current issues by focusing on stability, build-ability and cost efficiency and research done in IBS.

\section{Definition and types of IBS}

IBS is defined as a construction system which components are manufactured in a factory, on or off site, positioned and assembled into structure with minimum additional site work [5]. Dietz defined IBS as total integration of all sub-system and components into

\footnotetext{
Corresponding author: anissaggaff@yahoo.com
} 
overall process fully utilizing industrialized production, transportation and assembly techniques [6]. According to Parid (1997), IBS is a system which use industrialized production technique either in the production of component or assembly of the buildings or both [7]. Lessing et al defined IBS as an integrated manufacturing and construction process with well-planned organization for efficient management, preparation and control over resources used, activities and results supported by the used of highly developed component [8].

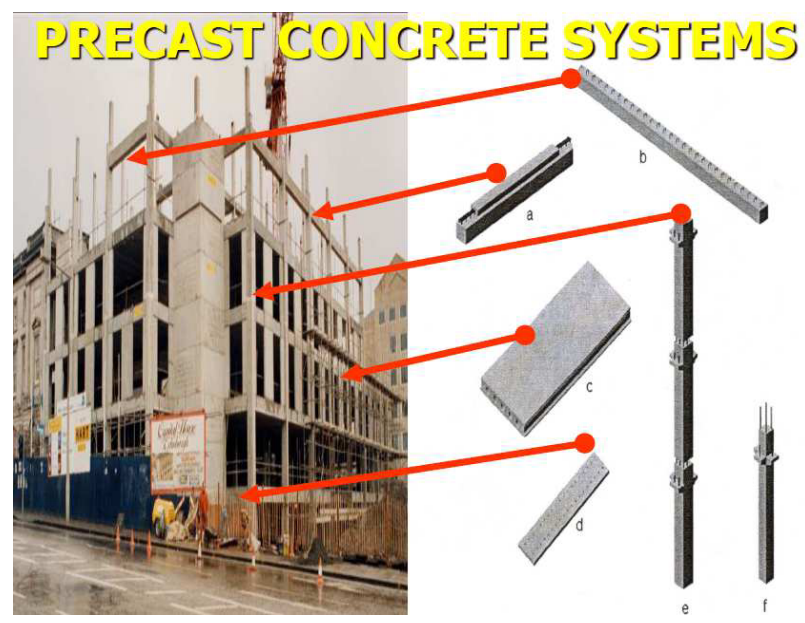

Fig. 1. Pre-cast concrete system

Nowadays, there is an increase in demand for housing due to an increase in population. In most countries including Indonesia, the demand is exceeding the supply. In order to solve the inadequacies of housing, Industrialized Building System (IBS) is introduced to replace conventional construction method. Basically, CIDB has classified IBS into five groups [3] which are

- Precast Concrete System (see Fig. 1)

- Steel Formwork Systems (see Fig. 2)

- Steel Framing Systems (see Fig. 3)

- Prefabricated Timber Framing Systems (see Fig. 4)

- Block Work Systems.

These systems are used due to several advantages. It saves a lot of time as the casting of precast structure can be done in factory and installed the construction components on site.[9] Besides, the delay in construction can be minimized as the construction components are fabricated in the factory with controlled environment [9].

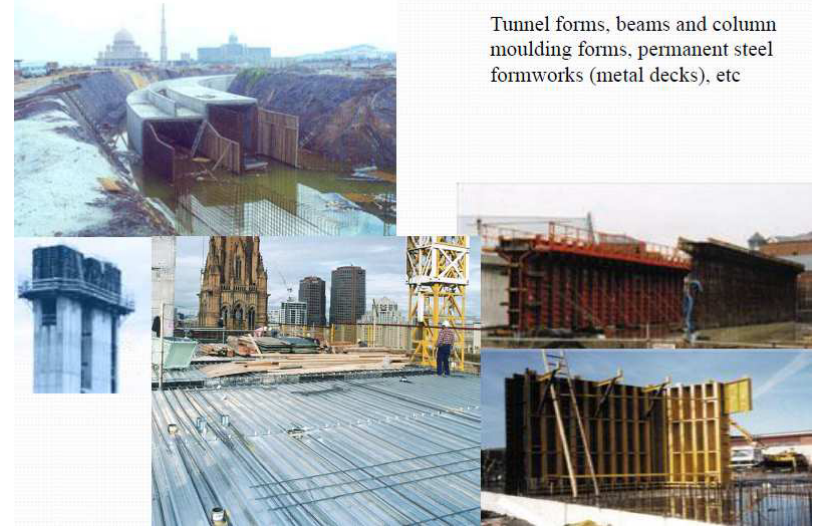

Fig. 2. Steel formwork system

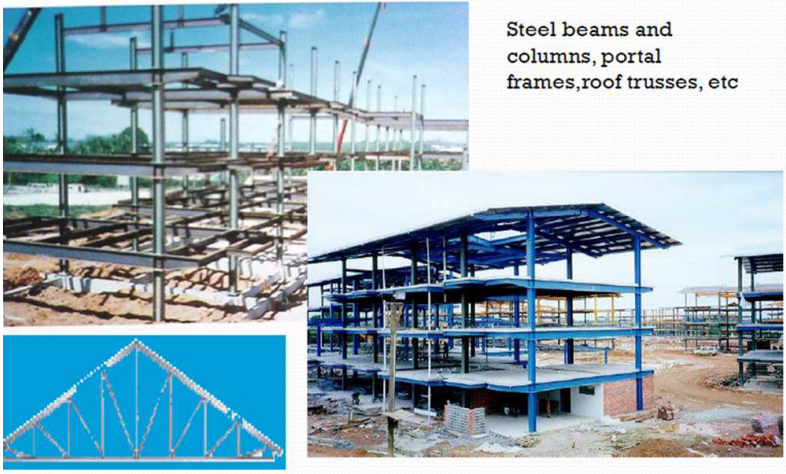

Fig. 3. Steel framing systems

\section{Advantages of IBS}

Awareness and knowledge are the main important barriers to the implementation of IBS in Malaysia [10]. Industrialized building system has the benefits when compared to the conventional construction method in the aspects of cost savings, less relied on labor, quality control, environmental friendly and less dependent on weather problem.

\subsection{Cost}

The implementation of the IBS in construction will reduce the construction time. CIDB [3-4] stated that the casting of the precast element in the factory and foundation at site can be carried out simultaneously. As the construction time decreases, the overall cost of the construction will also be reduced. Besides, the repetitive use of system formwork made up of steel and scaffolding can save the cost [11].

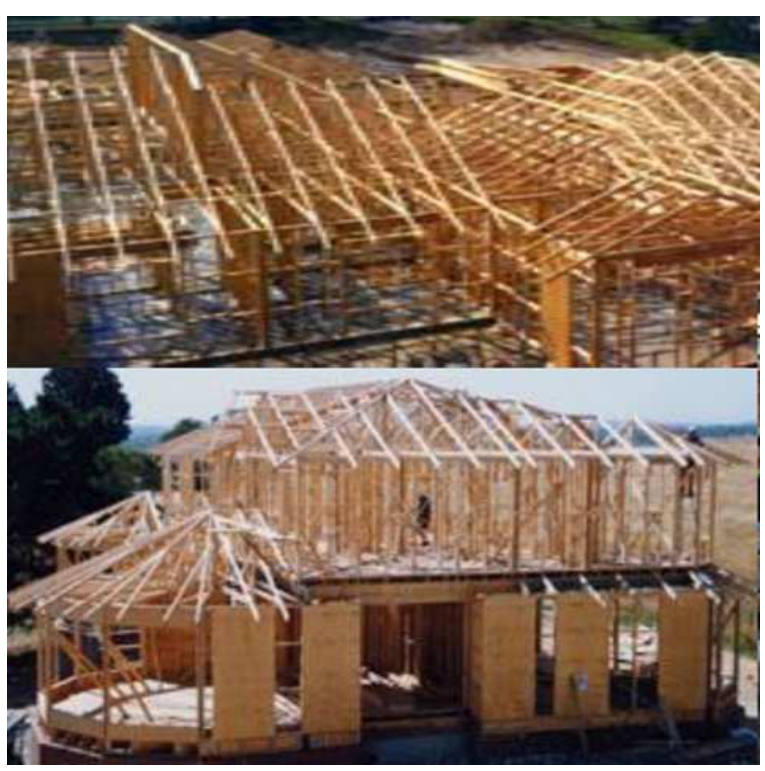

Fig. 4. Pre-fabricated timber frame system

\subsection{Labour}

Since IBS on mechanical means to produce prefabricated elements and only minimal in-situ construction, it reduces the requirement of labors for prefabrication of 
element and erection at site. Skilled and semi-skilled labors are needed for IBS and unskilled workers are mostly not needed. Countries like Malaysia where the construction industry is the host to a large number of foreign workers from Indonesia, Bangladesh and Pakistan. It is important to stress on that the labors are still have to send for training for the skills appropriate with the IBS. Although the training may cause some cost, it is believed that trained labor would be more quality than the untrained labor.

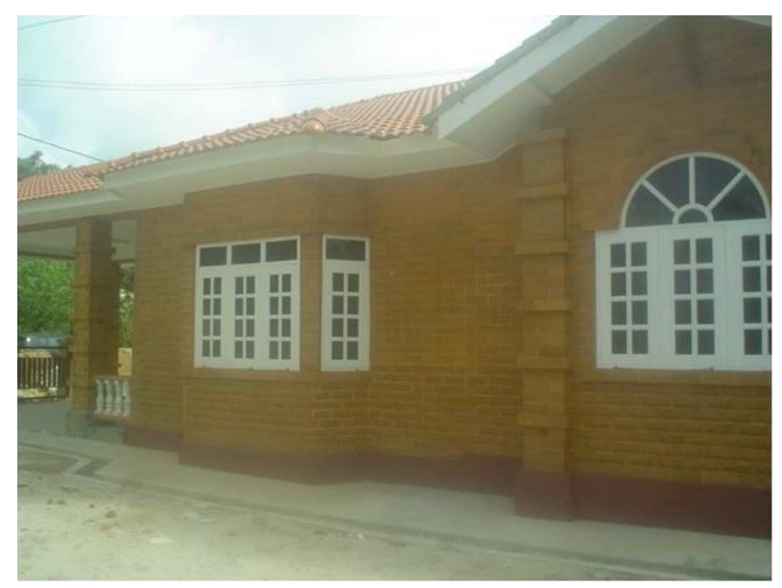

Fig. 5. Block work system

\subsection{Quality control}

The quality of the prefabricated concrete components in IBS is much better than the conventional method due to the quality in terms of the selection of materials, manufactured under controlled environment and inspection before the components send to the site. The materials used are based on the quality standard. Besides, the prefabricated concrete components are normally carried out in the factory which is indoor environment and it will not affected by the raining season in Malaysia. Inspection will be done to make sure the quality of the components is achieving the standard or the requirement needed by the clients.

The overall advantages of the using IBS system be summarized as shown in Fig. 6.

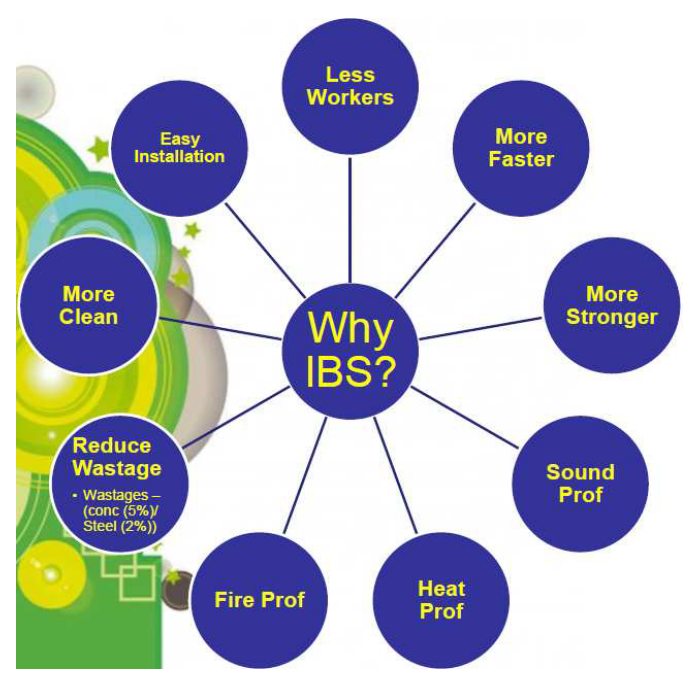

Fig. 6. Advantages of IBS

\section{Roadmap towards IBS}

Malaysia has earlier initiated the use of IBS by publishing IBS Roadmap 2003-2010 which prescribed the needs and requirements of Malaysian Construction industry [12]. The roadmap listed five main focus areas that are needed to drive forward the use of IBS in our construction industry in Malaysia. The five areas are listed as Manpower, Materials, Management, Monetary, and Marketing [13]. IBS Steering Committee was formed to enhance further the concept of IBS in the construction system [14]. The functions of the Steering Committee were to develop standard drawings for common use, to provide expertise in the process of development and production of IBS components, to carry out test and evaluation and to provide assistance in analysis and design procedures [14].

\subsection{Challenges and delays}

After all efforts done by the steering committee, shortcomings and delays of IBS implementation can be listed as follows [15]:

- IBS is not popular choice by consultant and developers due to lack of knowledge on the performance of the IBS system.

- The needs to change the mind-set of construction industry player that for long run IBS is much better than the traditional construction.

- Insufficient push factors from governments and policy makers such as Public Works Department and local authority.

- Lack of technical know-how from production to erection.

- Volume and initial cost of production are also issues to be addressed in the supplier chain.

Besides all the shortcomings and negative remarks mentioned above the way forward to implement the use of IBS are very much needed in order to benefit the advantages developed from IBS. A series of workshops to enhance awareness have been carried out by CIDB to all construction industry players. The awareness in using IBS has also been initiated by consultants, universities, and companies produce the IBS components.

\subsection{Planning and implementation}

The establishment of steering committee by Indonesia government should be seen as a very good step to inculcate IBS system in construction industry. One of the ways forward to enhance the effective planning and implementation of IBS is to promote research and development (R\&D) of IBS in all related parties in construction. The R\&D and workshops organized by Indonesia Construction Board should be carried out to the public so that the awareness of the IBS can be well accepted and understood. The initiatives to accept the use of IBS should be done by all parties such as contractors, consultants, universities, developers and research institutes. The main objectives of promoting the use of IBS is to ensure that factors such as improve the 
performance, quality, and minimize the dependency of unskilled workers and reduced cost can be well explained and understood. A complete and comprehensive study on IBS solutions which take into consideration the role of the entire value chain should be emphasized. A technology transfer model from other parts of developed countries should be done through smart collaboration.

\section{Some experimental works}

\subsection{Influence of longitudinal spaced bolted shear connectors on composite beam integrated with concrete and cold-formed steel}

[16] have experimented composite construction with conventional hot rolled steel (HRS) sections has been known to perform much better than Cold-formed steel (CFS) sections for decades. However, the composite action of CFS with an in-situ concrete, especially SelfCompacting Concrete (SCC) and bolted shear connector 'haven't been investigated'. This study attempted to investigate the behavior of bolted shear connector used with SCC and CFS as 'shear connector' to form a composite beam system at designated longitudinal spacing. Push-out test specimens of shear connector longitudinal spacing of $300 \mathrm{~mm}, 250 \mathrm{~mm}$ and $150 \mathrm{~mm}$ with bolted shear connector of grade 8.8.

Steel-concrete composite beam has being in use as a structural member in building and bridges for decades. The shear connection between steel and concrete slab in composite beams is inherently significant, as it resists separation between the two components as well as enhance longitudinal shear transfer.

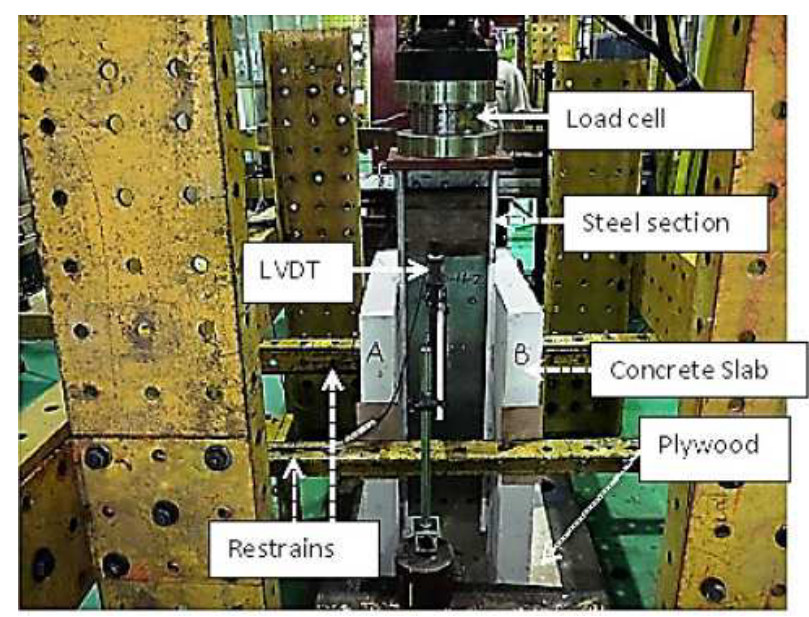

Fig. 7. Test of shear composite

The paper has come to summary that the effect of shear connector longitudinal spacing was investigated, and its influence on the ultimate strength capacity of the shear connector was established. The connection was classified as ductile shear connector since it attained a characteristic slip capacity. The longitudinal spacing of bolted shear connector had shown the influenced the strength capacity of the shear connector.

\subsection{Performance of varying bolted shear connectors in cold-formed steel composite beam}

Anis Saggaff study a suitable bolt and nut type of shear connection mechanism has been proposed. The Experiment has presented the possibility of using a type of bolt and nut as shear connector. The experimental tests results were conducted to ascertain the performance of the proposed connectors. The aim of the research was to investigate the structural performance of bolted shear connectors in providing composite action between Selfcompacting concrete (SCC) and CFS section integrated as composite beam system.

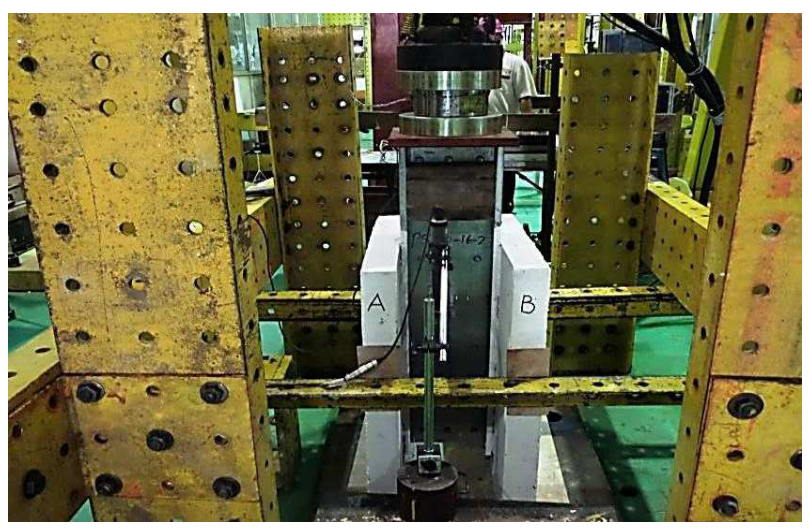

Fig. 8. Push-out test

The push-out test results have shown the load-slip relationships of the tested specimens. The specimens with M14 and M16 bolt diameters could be attributed to the failure of CFS section by flange local buckling. Perhaps high resistance of the applied load by the concrete slabs and bolted shear connectors could be responsible for it. The failure due to steel buckling occurred at the top shear connector position of specimens which was close to the load application position. The failure then extended upwards from the initial position where it had occurred to the part where the CFS was not covered by the concrete slab.

The Remarkable shear resistance and slips at ultimate loads were attained by the specimens with all the bolted shear connectors. It has proved that the maximum design capacity of the specimens with M14 and M16 bolted shear connectors is based on the tested value obtained due to CFS failure.

The study has shown the influence of shear connectors. The shear strength capacity of bolted shear connectors was noted as follows:

$40.6 \%$ between M12 and M14

$41.0 \%$ between M12 and M16 and

$0.3 \%$ between M14 and M16.

It was concluded that the shear connectors with single embedded nut and washer influence on the ultimate strength capacity of bolted shear connectors. The bolted shear connectors used in this study possessed good shear resistance capacity. 


\subsection{Behavior of pad footing with cold-formed lipped C-Channels steel section as permanent form-work}

Anis Saggaff has done the experimental work using light concrete and cold-formed steel with wire-mesh as reinforcement. The experimental investigation of pad footing designed using cold-formed lipped C-channel steel section as permanent formwork. The tested specimens assembled as square and rectangular padfooting where cold-formed steel of lipped C-channel section.
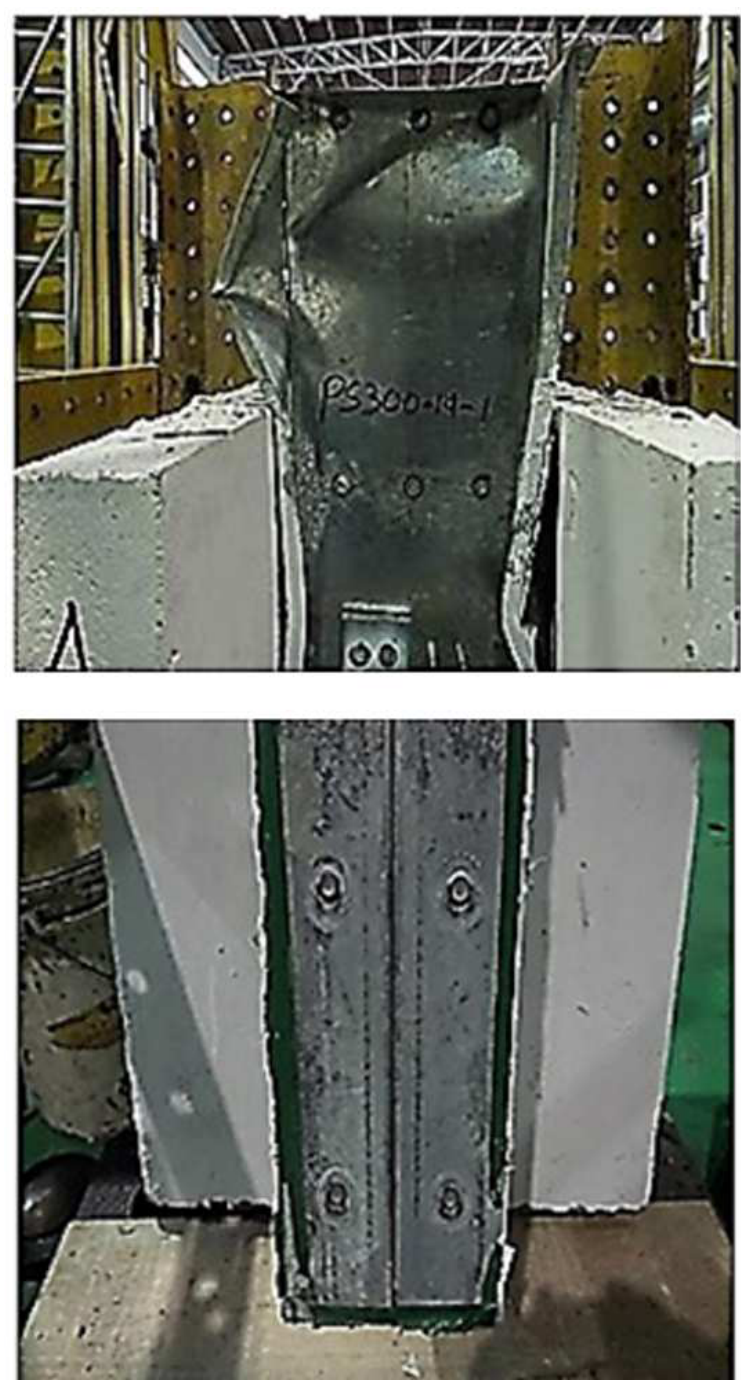

Fig. 9. Failure of shears

The formation of the formwork for each specimen was done using the lipped cold-formed steel section with stiffeners positioned at right angle to shape the footing as a boxed type specimen and to avoid changes in shape during concreting. The reinforcement bars used in the LCCFSS specimens were A10 which was bent downward about the length of the cover needed for the footing and sit on the LCCFSS specimen as shown in. This was purposely done so that no spacer is needed underneath the A10 wire mesh to meet the requirement of the concrete cover. For typical reinforced concrete pad footing the A10 wire mesh was bent upward which result to the need of the spacer underneath the reinforcement to meet the requirement of concrete cover. Test results has shown the maximum axial load applied until failure based on the theoretical calculation from BS 8110 part 1:1997 [12]. The load capacity of the footing also depends on the length of the footing besides the thickness of the footing. This study has maintained the thickness is kept constant. The load capacity of the footing has been reduced by up to $30 \%$ as the length of the footing increased from $1000 \mathrm{~mm}$ to $1750 \mathrm{~mm}$. The reduced in load capacity is very much related to the failure of the footing which is shifted from punching shear failure to bending failure.
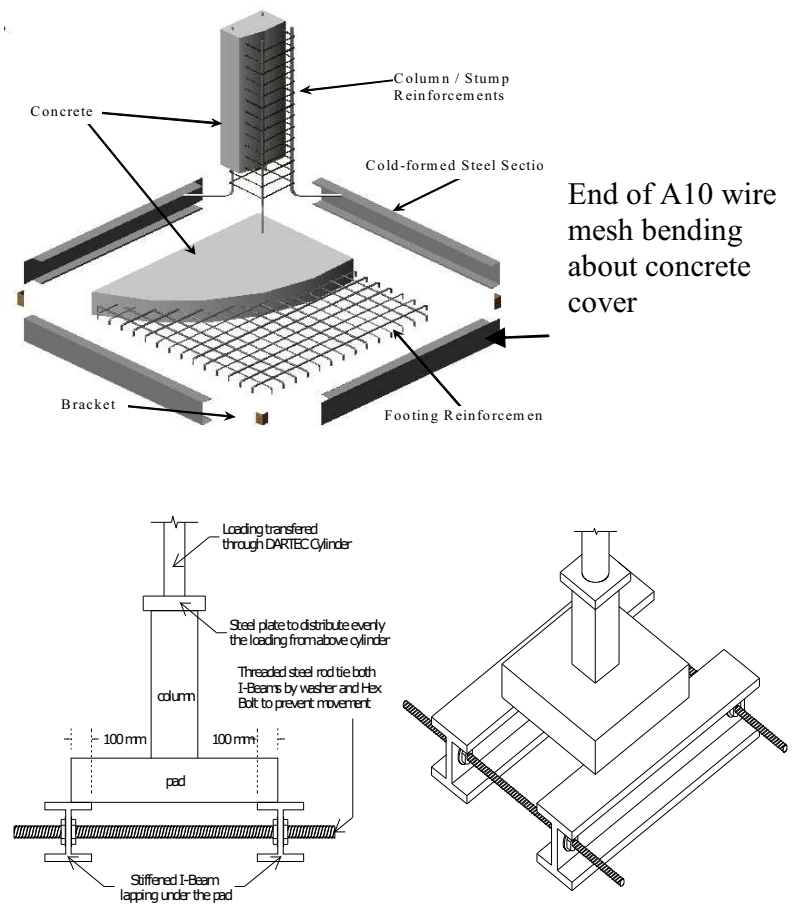

Fig. 10. Layout of test setting

\section{Conclusions}

The use of IBS system needs all construction players to adopt or willing to accept the way forward in construction industry. It is hoped that the finding addressed in this paper could highlight the benefits of using IBS in actual construction. It is also hoped that the IBS can be used to solve the problem of housing needs in Indonesia. The delays in implementation should not hinder the way forward in construction as the benefits of using IBS are too many to be ignored. Indonesia government should take a drastic measures and regulation in order to prosper the success of IBS in Indonesia.

The author of this paper would like to acknowledge Specials thanks addressed to Construction Research Center UTM, Prof Ir. Dr Mahmood Md Tahir., and Structure and Construction Research Center also Sriwijaya University that make this paper 


\section{References}

1. Pupera, The Ministry of Public Works and Housing Report (PUPERA, Indonesia, 2016)

2. CIDB Malaysia, Strategic recommendations for improving environmental practices in construction industry (CIDB Publisher, Kuala Lumur, 2007a)

3. CIDB Malaysia, Guidelines for implementing environmental management system in the construction industry (CIDB Malaysia, Kuala Lumpur, 2007b)

4. Hervas, Open Building Manufacturing - Core Concept and Industrial Requirements (Manu BUILD Consortium, Holland, 2007)

5. National IBS Survey, Construction Industry Development Board (CIDB) (CIDB, Malaysia, Kuala Lumpur, 2003)

6. A. G. H. Diets, Global Trends in Research Development and Construction Proceeding of the International Conference of the International Conference on Industrialised Building System (IBS CIDB Malaysia, Kuala Lumpur, 2003)

7. W. Parid, Global Trends in Research Development and Construction Proceeding of the International Conference of the International Conference on Industrialised Building System (IBS, CIDB Malaysia, Kuala Lumpur, 2003)

8. J. Lessing, A. Ekholm, and L. Stehn, $13^{\text {th }}$ International Group for Lean Construction (Sydney, Australia, 2005)
9. T. M. Toole, J. CEM, 124, 4, (1998)

10. M. M. Nuruddin, Buletin Bulanan Jurutera (Institute of Engineers Malaysia, 2003)

11. CIDB Malaysian, Construction Industry Technology Foresight Report (CIDB Malaysia, 2000)

12. Construction Industry Master Plan 2006 - 2015 (CIDB, Kuala Lumpur, 2007)

13. S. S. Gue, Bridging the Gap between $R \& D$ and Construction Industry", (CIDB, PWTC, Kuala Lumpur, 2007)

14. J. Hussein, Industrialized Building System: The Challenge and The Way Forward (CIDB PWTC, Kuala Lumpur, 2007)

15. A.H. Zuhari, K.G. Mohd, H.A.R. Ahmad and A.M.K. Kamal, Industrialised Building Systems (IBS): Current Shortcomings and the Vital Roles of $R \& D$ (JURUTERA, Malaysia, 2008)

16. M. M. Lawan, M Tahir, J. Mirza, and A. Saggaff, Influence of Longitudinal Spaced Bolted Shear Connectors on Composite Beam Integrated with Concrete and Cold-Formed Steel (2008)

17. A. Sagaff, M. M. Lawan, M Tahir, and J. Mirza, Performance of Varying Bolted Shear Connectors in Cold Formed Steel Composite Beam (2008)

18. A. Saggaff, M. Tahir, W. K. Leong, and S. P. Ngian, Behavior of Pad Footing with Cold-formed Lipped C-Channels Steel Section as Permanent Form-Work (2016)

* Corresponding author: anissaggaff@yahoo.com 